\title{
Aplikasi Data Gudang Sparepart Pada Toko Prima Jaya Aek Nabara Menggunakan Visual Basic.Net
}

\author{
Kusmanto $^{1}$, Ronal Watrianthos ${ }^{2}$ \\ ${ }^{1}$ Universitas Al Washliyah Labuhanbatu, Rantauprapat, Indonesia
}

\begin{tabular}{l} 
Info Artikel \\
\hline Article history: \\
Received: 2142019 \\
Revised: 13052019 \\
Accepted: 28062019 \\
Kata Kunci: \\
Aplikasi Data Gudang \\
Sparepart
\end{tabular}

Penulis Korespondensi: kusnabara03@gmail.com

\begin{abstract}
At this time, the process of recording the inventory data of Toko Prima Jaya Aek Nabara was still done manually, especially in terms of recording data on incoming and outgoing goods and making reports. With such a system it causes frequent errors that can have an impact on the overall inventory of goods. With the development of this application, it will help the process of transactions for the exit and entry of goods to be more efficient. In building applications using Visual Basic.Net 2008. If this application is used it is expected to make it easier to provide information to leaders and the resulting reports are effective data.
\end{abstract}

\begin{abstract}
Abstrak
Pada saat ini proses pencatatan data persediaan barang pata Toko Prima Jaya Aek Nabara masih dilakukan secara manual, terutama dalam hal pencatatan data masuk dan keluarnya barang serta pembuatan laporan-laporan. Dengan sistem seperti itu menyebabkan sering terjadinya kesalahan yang dapat berdampak pada persediaan barang secara keseluruhan. Dengan dibangunnya aplikasi ini akan membantu proses transaksi keluar dan masuknya barang agar lebih efisien. Dalam membangun aplikasi menggunakan Visual Basic.Net 2008. Apabila aplikasi ini digunakan maka diharapkan dapat mempermudah memberikan informasi kepada pimpinan dan laporan yang dihasilkan merupakan data yang efektif.
\end{abstract}

\section{PENDAHULUAN}

Pada saat ini teknologi informasi sudah berkembang di berbagai bidang kehidupan, teknologi informasi tak mudah terlepas dari semua kalangan seperti sudah menjadi suatu kebutuhan, mulai banyak memanfaatkan dan menggunakan teknologi informasi.[1] Keberadaan3. teknologi pengolahan data menjadi informasi secara terkomputerisasi menjadi penting, jika dibandingkan pengolahan data secara manual, pengolahan data secara terkomputerisasi dapat memberikan kecepatan, keakuratan pemerosesan data dan mendukung data dalam skala yang cukup besar.[2]

Toko Prima Jaya merupakan sebuah toko yang bergerak di bidang penjualan sparepart sepeda motor dan melayani jasa service sepeda motor. Seiring dengan perkembangan teknologi informasi, Toko Prima Jaya perlu memanfaatkan teknologi informasi untuk meningkatkan kinerja agar menghasilkan data yang tepat dan akurat. Toko Prima Jaya dalam menangani pendataan sparepart sepeda motor, penjualan dan pembelian masih secara manual yaitu pencatatan setiap transaksi dengan menggunakan buku besar, sehingga pembuatan laporan membutuhkan waktu yang tidak sedikit.

\section{LANDASAN TEORI}

\subsection{Internet}

Aplikasi menurut kamus komputer adalah program software atau paket program yang dibuat untuk melaksanakan suatu fungsi bagi penguna (program siap pakai). Aplikasi akan menggunakan sistem operasi (OS) komputer yang mendukung. Biasanya istilah aplikasi dipakai dengan nama program , misalnya aplikasi MS Word.[3]

Menurut Fathansyah, (2012:16). Aplikasi (perangkat lunak) bersifat optimal, ada atau tidaknya tergantung kebutuhan kita, DBMS yang kita gunakan lebih berperan dalam pengorganisasian data dalam 
basis data, sementara bagi pemakai basis data dapat dibuatkan program khusus untuk melakukan pengisian, pengubahan dan pengambilan data.[4]

\subsection{Data}

Menurut Gordor B. Davis (1985). Data berasal dari bahasa latin yaitu "datum", yang berarti fakta, kenyataan, kejadian, atau peristiwa. Jadi data adalah fakta dasar yang mewakili suatu kejadian. Data di proses oleh sistem komputer untuk menghasilkan informasi.[5] Menurut Al Bahra bin Ladjamudin (2005), Data dapat berupa angka dalam berbagai bentuk. Menurut Teguh Wahyono, (Sistem Informasi Konsep Dasar, Analisis Desain dan Implementasi), 2004; 2-3).[6]

\subsection{Gudang}

Menurut Yunarto dan Santika terdapat beberapa tipe gudang seperti: retail warehouse (Gudang ritel), central warehouse (Gudang Pusat), manufacturing warehouse (Gudang Manufaktur), dan distribution warehouse (Gudang Distribusi).[6] Gudang memiliki fungsi sebagai tempat untuk menyimpan barang mentah, barang setengah jadi, dan barang yang siap untuk dipasarkan ataupun alat pekerja.[7]

\subsection{Suku Cadang (Sparepart)}

Menurut Yoseph (2013:44) dalam jurnal yang ditulisnya, "sparepart adalah suku cadang yang digunakan untuk menggantikan komponen yang mengalami kerusakan pada suatu unit mesin". Menurut Kotler, (1997:15), sparepart adalah suatu barang yang terdiri dari beberapa komponen yang membentuk satu kesatuan dan mempunyai fungsi tertentu.[8]

\subsection{Vsual Basic.Net}

Microsoft Visual Studio 2008 atau Visual Basic.Net merupakan aplikasi pemrograman yang menggunakan teknologi .Net Framework. Teknologi .Net Framework merupakan komponen windows yang terintegrasi serta mendukung pembuatan, penggunaan aplikasi, dan halaman web. Menurut Budiarto (2002:95), [9]Visual Basic adalah salah satu bahasa pemrograman komputer yang digunakan untuk aplikasi windows yang berbasis GUI (Graphical User Interface). Visual Basic merupakan event-driven programming (Pemrograman terkendali kejadian) artinya program menunggu sampai adanya respon dari pemakai berupa kejadian tertentu (tombol di klik, menu dipilih, dan lain-lain).[10]

\subsection{Microsoft Access}

Menurut Taufani (2009:1) Microsoft Access 2007 atau lebih dikenal dengan sebutan Access 2007 merupakan salah satu aplikasi yang diperuntukkan untuk mengolah database di bawah sistem Windows. Aplikasi yang merupakan salah satu aplikasi berbasis data relasional bagian dari Microsoft Office ini ditujukan kepada kalangan perusahaan kecil hingga perusahaan menengah yang dikhususkan untuk perancangan dan pengolahan berbagai macam database.[11] yang menyediakan fasilitas seperti tabel sebagai objek utama dalam database yang digunakan untuk menyimpan sekumpulan data sejenis dalam sebuah objek, query yang merupakan suatu bahasa untuk melakukan manipulasi terhadap database yang digunakan untuk menampilkan, mengubah dan menganalisis sekumpulan data, form digunakan untuk mengontrol proses masukan data (input), menampilkan data (output), memeriksa dan memperbaharui data dan report yang berfungsi untuk menampilkan data yang sudah dirangkum dan mencetak data yang di input.[12]

\section{ANALISA DAN PERANCANGAN}

\subsection{Analisa}

Pada saat ini, prosedur yang diterapkan pada toko prima jaya Aek Nabara dalam pendataan persediaan barang, laporan penjualan dan pembeliannya masih semuanya secara menual. Setiap pengolahan data transaksi baik transaksi pendataan persediaan barang, pembelian maupun penjualan masih menggunakan sistem pencatatan pada buku besar, sehingga sering terjadi kesulitan dalam pengontrolan persediaan barang, kesulitan dalam pembuatan laporan penjualan dan pembelian yang membutuhkan waktu lama dalam pencarian data barang.[13]

\subsection{Perancangan}

\subsubsection{Flowcart login}

Kasir dan pimpinan melakukan input login pada manu login sistem kemudian sistem melakukan verifikasi bahwa login berhasil atau tidak, jika login tidak berhasil maka akan kembali pada menu login sistem dan apabila berhasil maka akan masuk pada menu sistem.[14] 


\section{IMPLEMENTASI}

\subsection{Kebutuhan Sistem}

Implementasi merupakan tahap dari aplikasi yang sudah dibangun dan dirancang. Selanjutnya dilakukan uji kelayakan terhadap aplikasi sehingga user dapat memberikan masukan demi berkembangnya aplikasi yang telah dibangun.[9] Adapun aplikasi yang telah dibangun adalah aplikasi data gudang sparepart. Selain itu, dibutuhkan perangkat keras dan perangkat lunak yang digunakan untuk melakukan implementasi dan pengujian terhadap aplikasi[12] yaitu sebagai berikut:

1. Perangkat keras (Hardware) yang digunakan untuk analisis dan perancangan sistem adalah :

a. Processor Intel dual core

b. Monitor Lcd 11.1 Inc

c. VGA Card $512 \mathrm{mb}$

d. RAM 1 GB

e. Keyboard

f. Mouse

g. Harddisk $128 \mathrm{gb}$

1. Perangkat lunak (Software) yang digunakan untuk analisis dan perancangan sistem :

a. Windows 7

b. Microsoft Visual Studio 2008

\subsection{Tampilan Program}

1. Tampilan form login

Tanpilan ini merupakan tampilan awal pada aplikasi, dimana terdapat beberapa menu yaitu:

- User Name merupakan untuk memasukan nama pengguna yang kita buat sebelumnya di database.

- Password merupakan untuk memasukan password yang telah kita nuat sebelumnya di database.

- Login untuk memulai aplikasi apabila user name dan password sudah kita masukan.

- Batal untuk membatalkan yang sudah kita masukan di kolom user name dan password.

- Tutup untuk keluar dari proses login.

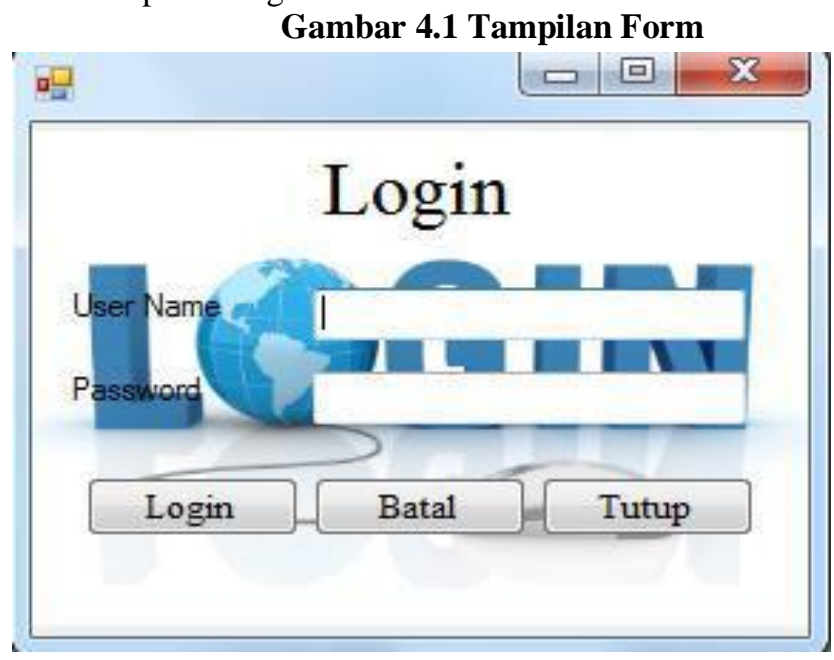

2. Tampilan Form Menu Utama

Tampilan ini merupakan tampilan menu utama setelah kita berhasil dalam proses login, dimana juga terdapat beberapa menu yaitu:

- Data, untuk memilih data yang akan kitamasukan.

- Transaksi, untuk mengetahui transaksi penjualan yang dilakukan setiap harinya.

- Laporan, untuk memilih laporan yang akan kita lihat.

- Ganti Password, untuk merubah password yang sudah kita buat.

- Keluar Aplikasi, untuk keluar aplikasi 


\section{Gambar 4.2 Tampilan Form Menu Utama}

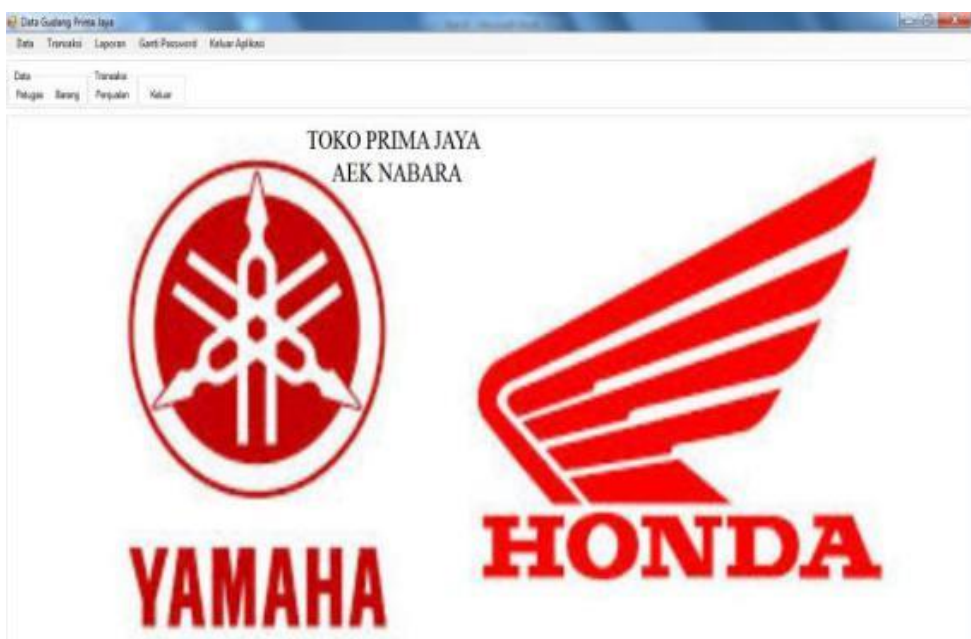

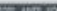

3. Tampilan form data petugas

Tampilan ini merupakan mengelola data petugas, dimana terdapat beberapa menu yaitu:

- Kode petugas, untuk memasukan kode petugas yang kita inginkan.

- Nama petugas, untuk memasukan nama petugas yang kita inginkan.

- Password, untuk memasukan password yang kita inginkan

- Status, merupakan informasi sebagai apa kita masuk di dalam aplikasi, dan dibuat sesuai kebutuhan.

- Simpan, merupakan pilihan jika kita sudah memasukan semua yang sudah kita ketikan tadi dan akan muncul otomotis di bagian bawah.

- Hapus, merupakan pilihan untuk menghapus data petugas yang sudah kita masukan, tetapi sebelum itu kita harus memastikan semua kolom sudah ada.

- Batal, merupakan pilihan untuk menbatalkan jika kita tidak ingin menghapus atau menyimpan data petugas.

- Tutup, merupakan keluar menu pengelola data petugas.

Gambar 4.3 Tampilan Form Data Petugas

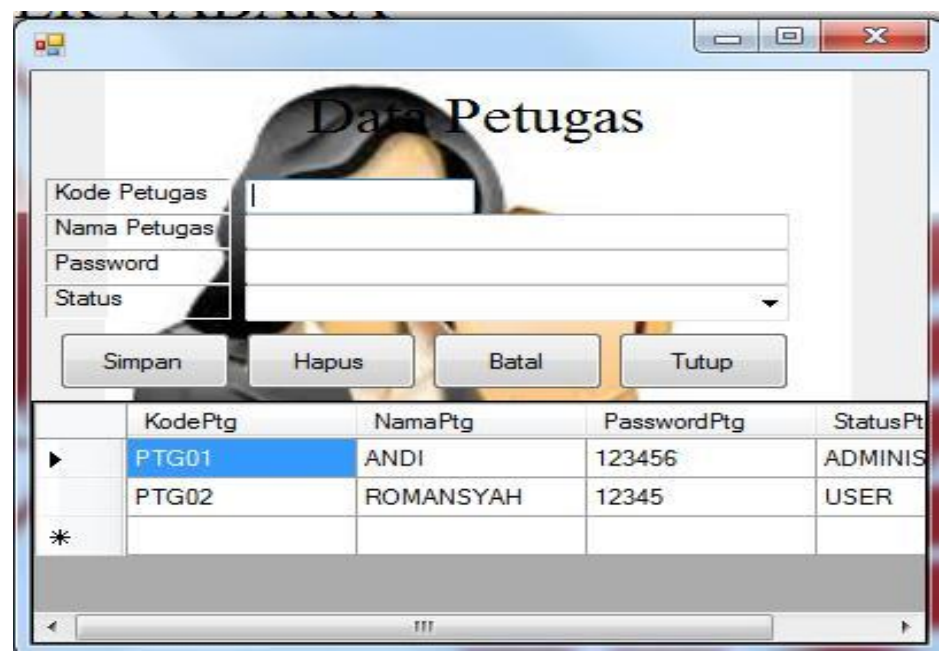

4. Tampilan Form barang

Tampilan ini merupakan mengelola data barang dari supplier, dimana terdapat beberapa menu yaitu:

- Kode barang, untuk memasukan kode barang yang kita inginkan.

- Nama barang, untuk memasukan nama barang yang kita beli dari supplier. 
- Harga beli, untuk memasukan harga beli dari supplier.

- Harga jual,untuk memasukan harga jual sesuai yang diingikan oleh pimpinan toko.

- Jumlah barang, untuk memasukan jumlah barang yang kita beli daro supplier.

- Satuan, untuk memasukan satuan barang yag kita beli dari supplier

- Simpan, merupakan pilihan jika kita sudah memasukan semua yang sudah kita ketikan tadi dan akan muncul otomotis di bagian bawah.

- Hapus, merupakan pilihan untuk menghapus data barang yang sudah kita masukan, tetapi sebelum itu kita harus memastikan semua kolom sudah ada.

- Batal, merupakan pilihan untuk menbatalkan jika kita tidak ingin menghapus atau menyimpan data barang.

- Tutup, merupakan keluar menu pengelola data petugas.

Gambar 4.4 Tampilan Form Barang

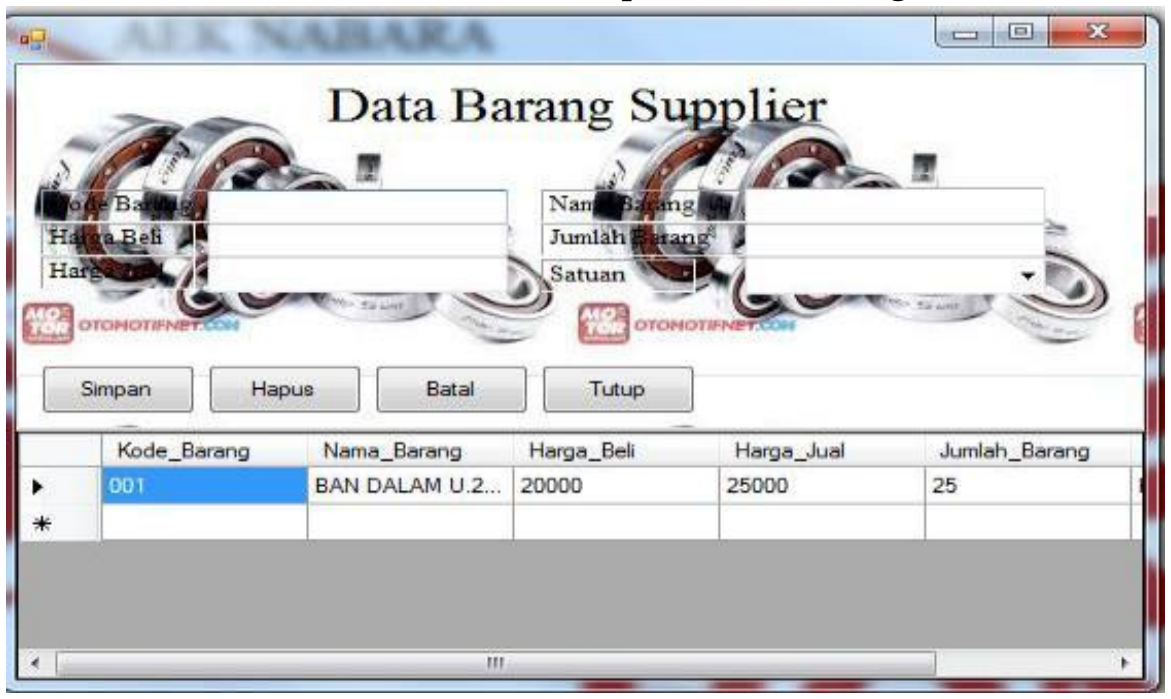

5. Tampilan form transaksi penjualan

Tampilan ini merupakan mengelola data transaksi penjualan, dimana terdapat beberapa menu yaitu:

- Faktur, secara otomatis sudah ada ketika kita membuka menu transaksi tanpa kita memasukan nya.

- Tanggal, secara otomatis sudah ada ketika kita membuka menu transaksi tanpa kita memasukan nya.

- Jam, secara otomatis sudah ada ketika kita membuka menu transaksi tanpa kita memasukan nya.

- Kita lihat ada tabel di dalam menu, di gunakan untuk memasukan kode barang yang akan kita beli dengan cara melihat kode barang yang kita masukan di menu barang.

- Item, secara otomotis terisi ketika memasukan jumlah barang yang akan dibeli, sesuai tabel yang berada di atas.

- Total, secara otomotis terisi berapa jumlah barang yang dibeli dangan harga barang yang sudah ada.

- Dibayar, untuk memasukan jumlah uang yang dibayarkan.

- Kembli, secara otomotis terisi bila kita kita tekan enter setelah kolom dibayar kita isikan.

- Simpan, merupakan pilihan jika kita sudah memasukan semua yang sudah kita ketikan tadi dan akan muncul otomotis faktur transaksi penjualan.

- Batal, merupakan pilihan untuk menbatalkan jika kita tidak ingin menyimpan atau membeli barang yang sudah kita pilih.

- Tutup, merupakan keluar menu pengelola data penjualan. 


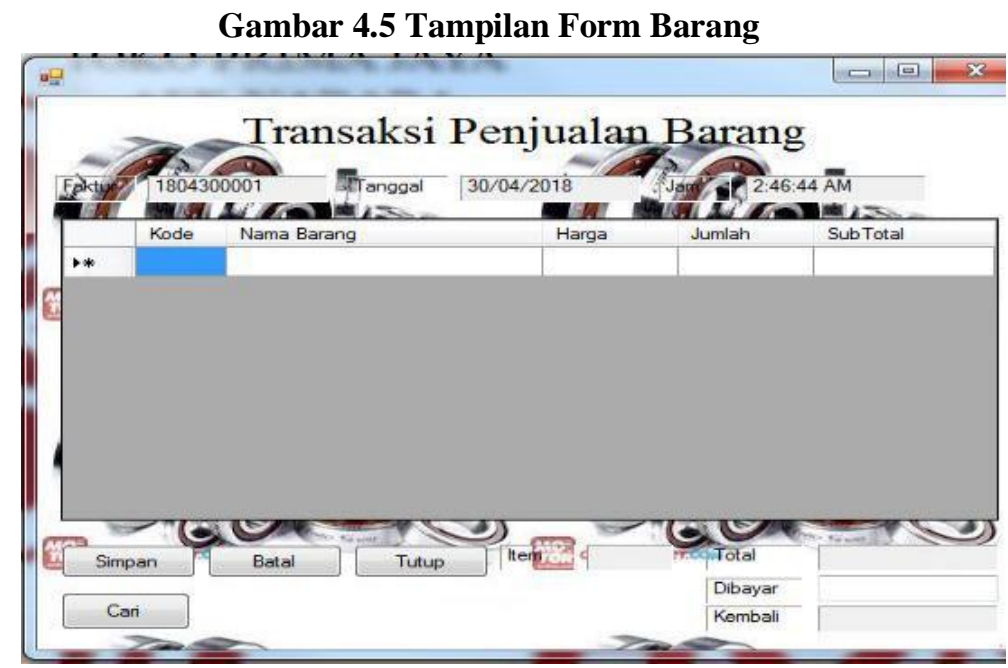

6. Tampilan form laporan data petugas

Tampilan ini untuk melihat informasi mengenai laporan data petugas yang kita masukan didalam form data petugas.

Gambar 4.6 Tampilan Form Laporan Data Petugas

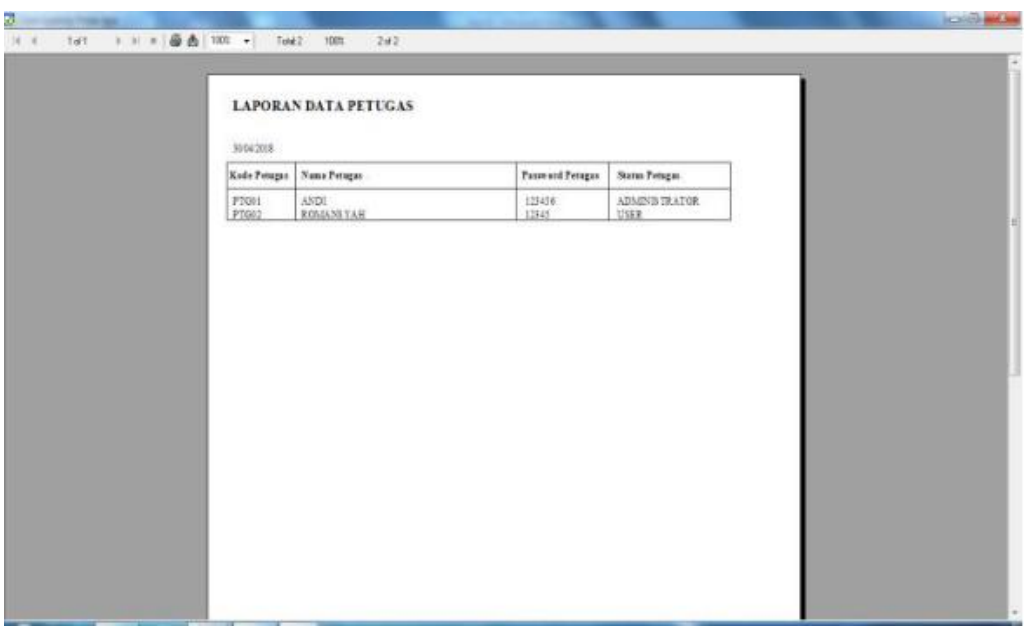

7. Tampilan form laporan data barang

Tampilan ini untuk melihat informasi mengenai laporan data barang yang kita masukan didalam form data barang.

\section{Gambar 4.7 Tampilan Form Laporan Data Barang}

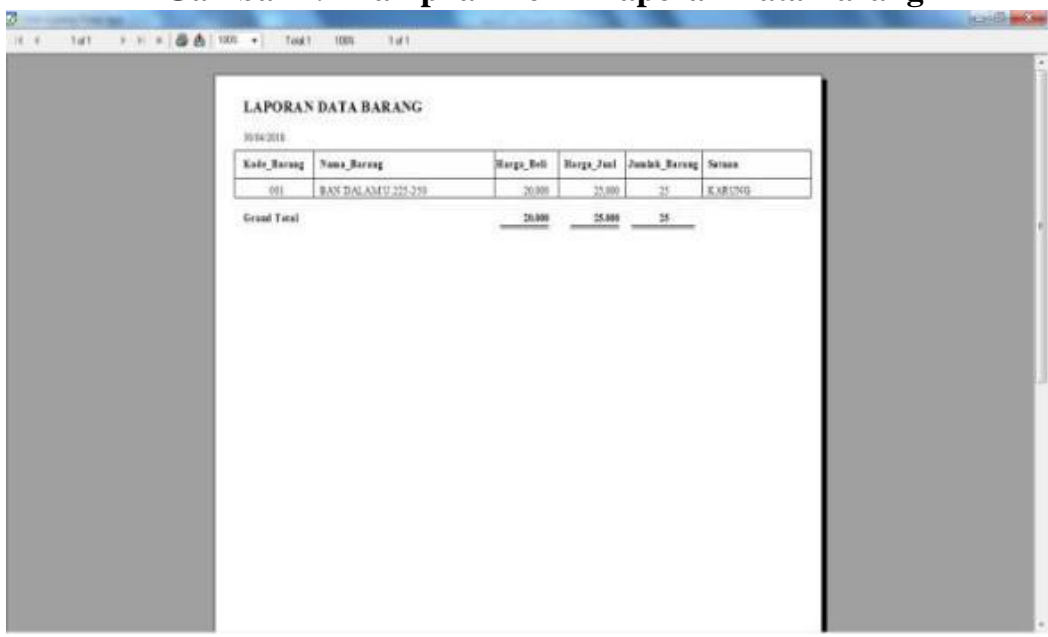


8. Tampilan form laporan data penjualan

Tampilan ini untuk melihat informasi mengenai laporan data penjualan yang kita masukan didalam form data transaksi penjualan yang terdiri:

- Laporan Harian

- Laporan Mingguan

- Laporan Bulanan

Gambar 4.7 Tampilan Form Laporan Data Penjualan

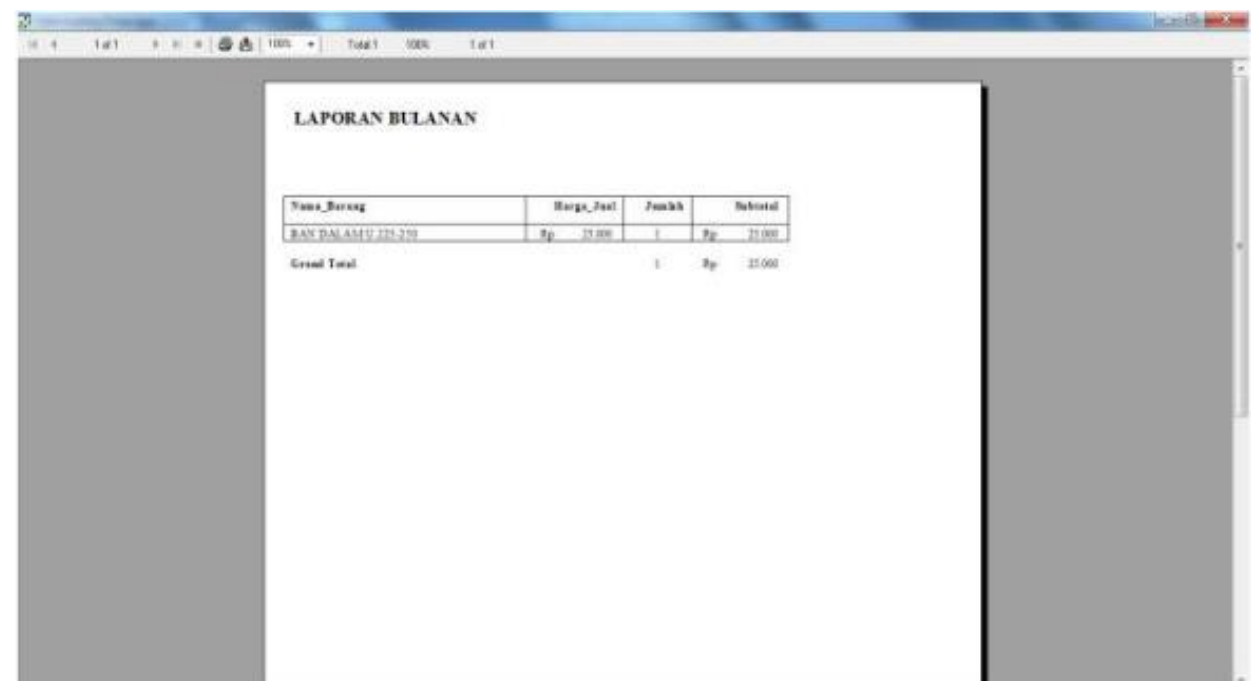

\section{KESIMPULAN DAN SARAN}

\subsection{Kesimpulan}

Berdasarkan dari analisis aplikasi yang telah dilakukan terhadap aplikasi yang berjalan sekarang pada Toko Prima Jaya Aek Nabara, maka peneliti disimpulkan sebagai berikut :

1. Dengan menggunakan Visual Basic.Net diharapkan dapat membantu penyimpanan data transaksi penjualan, persediaan barang, serta laporan barang dan laporan penjualan.

2. Kasir dan pemilik toko Prima Jaya mudah dalam pengecekan barang apakah barang sudah diterima atau barang sudah masuk ke gudang.

3. Memudahkan seorang kasir dalam pencarian data barang.

\subsection{Saran} berikut :

Berdasarkan kesimpulan yang telah dipaparkan dalam penelitian ini, ada beberapa saran yaitu sebagai

1. Agar kasir dapat menjalankan program ini sebaik mungkin dan selalu mengikuti prosedur penginputan data agar pendataan barang dan penjualan sesuai yang diharapkan.

2. Dalam memasukan transaksi penjualan serta persediaan sparepart diharapkan ketelitian kasir dalam pemasukan data laporan untuk menghindari terjadi kesalahan pembuatan laporan data barang dan laporan data penjualan. 


\section{REFERENSI}

[1] D. I. G. H. Wirhan Fahrozi, Samsir, "Penerapan E-Commerce Pada Toko Bunga Underwear," J. Tek. Inform., vol. 04, no. 01, pp. 1-6, 2020.

[2] M. Siddik and S. Samsir, "Rancang Bangun Sistem Informasi Pos (Point of Sale) Untuk Kasir Menggunakan Konsep Bahasa Pemrograman Orientasi Objek," JOISIE (Journal Inf. Syst.

Informatics Eng., vol. 4, no. 1, p. 43, 2020, doi: 10.35145/joisie.v4i1.607.

[3] Samsir, D. I. G. Hts, and S. Z. Harahap, "SPK Untuk Pemilihan Kepala Sekolah Menggunakan Metode Saw dan Profile Matching," U-NET J. Tek. Inform., 2020.

[4] Samsir and Syaiful Zuhri Harahap, "Application Design Resume Medical By Using Microsoft Visual Basic. Net 2010 At the Health Center Appointments," Int. J. Sci. Technol. Manag., vol. 1, no. 1, pp. 14-20, 2020, doi: 10.46729/ijstm.v1i1.5.

[5] S. Samsir, S. Suparno, and M. Giatman, "Predicting the loan risk towards new customer applying data mining using nearest neighbor algorithm," IOP Conf. Ser. Mater. Sci. Eng., vol. 830, no. 3, 2020, doi: 10.1088/1757-899X/830/3/032004.

[6] R. Watrianthos, Y. Triyanto, P. Pristiyono, D. Hasibuan, and S. Samsir, "e-Government Village Model," 2020, doi: 10.4108/eai.11-12-2019.2290857.

[7] R. A. Purba, S. Samsir, M. Siddik, S. Sondang, and M. F. Nasir, "The optimalization of backpropagation neural networks to simplify decision making," IOP Conf. Ser. Mater. Sci. Eng., vol. 830, no. 2, 2020, doi: 10.1088/1757-899X/830/2/022091.

[8] Syaiful Zuhri Harahap and Samsir, "Application Design The Data Collection Features of The Hotel Shades of Rantauprapat Using VBNET," Int. J. Sci. Technol. Manag., 2020, doi: 10.46729/ijstm.v1i1.4.

[9] F. Edi, P. T. Informatika, and F. U. A. Labuhanbatu, "UNET | Jurnal Ilmiah Teknik Informatika LPPM Universitas Al Washliyah Labuhanbatu UNET | Jurnal Ilmiah Teknik Informatika ISSN . 2460-3694, Vol . 2 No . 1 Februari 2018,” vol. 2, no. 1, pp. 2-5, 2018.

[10] J. H. P. Sitorus et al., "Perancangan pengontrol lampu rumah miniatur dengan menggunakan micro controler arduino berbasis android 1," vol. 4, no. 1, pp. 1-11, 2020.

[11] M. V. B. Net, "PADA TOKO URIP MOTOR," no. September, pp. 1-6, 2020.

[12] Samsir, "Klasifikasi Penyakit Tenggorokan Hidung Telinga ( THT ) Menggunakan Jaringan Syaraf Tiruan Dengan Metode Learning Vektor Quantization ( THT ) Di RSUD Rantauprapat Labuhanbatu Klasifikasi penyakit Tenggorokan Hidung Telinga ( THT ) Menggunakan,” vol. 05, no. 01, pp. 3847, 2019.

[13] S. Zulkifli, "Implementasi Sistem Keamanan SQL Injection Dalam berbasis web," Ejurnal.Univalabuhanbatu.Ac.Id, vol. 04, no. 01, pp. 13-17, 2020, [Online]. Available: https://ejurnal.univalabuhanbatu.ac.id/index.php/u-net/article/download/164/130.

[14] U. Verawardina, F. Edi, and R. Watrianthos, "Analisis Sentimen Pembelajaran Daring Pada Twitter di Masa Pandemi COVID-19 Menggunakan Metode Naïve Bayes," vol. 5, pp. 157-163, 2021, doi: 10.30865/mib.v5i1.2604. 